\title{
The association between fasting blood glucose and the risk of primary liver cancer in Chinese males: a population-based prospective study
}

Xiaoshuang Feng ${ }^{1}$, Gang Wang ${ }^{2}, \mathrm{Ni} \mathrm{Li}^{*}, 1$, Zhangyan Lyu ${ }^{1}$, Shuohua Chen ${ }^{3}$, Luopei Wei ${ }^{1}$, Yuheng Chen ${ }^{1}$, Shuanghua Xie ${ }^{1}$, Wenjing Yang ${ }^{1}$, Jian Yin ${ }^{1}$, Hong Cui ${ }^{1}$, Hongda Chen ${ }^{1}$, Jiansong Ren ${ }^{1}$, Jufang Shi ${ }^{1}$, Shouling $\mathrm{Wu}^{3}$, Min Dai ${ }^{*, 1}$ and Jie $\mathrm{He}^{1}$

${ }^{1}$ National Cancer Centre/Cancer Hospital, Chinese Academy of Medical Sciences and Peking Union Medical College, Beijing 100021, China; ${ }^{2}$ Department of Oncology, Kailuan General Hospital, Tangshan 063000, China and ${ }^{3}$ Health Department of Kailuan (group), Tangshan 063000, China

Background: To investigate the association between fasting blood glucose (FBG) levels and the risk of incident primary liver cancer (PLC) in Chinese males, a large prospective cohort was performed in the current study.

Methods: A total of 109169 males participating in the routine checkups every two years were recruited in the Kailuan male cohort study since May 2006. Cox proportional hazards regression models and restricted cubic spline (RCS) were used to evaluate the association between levels of baseline FBG and the risk of incident PLC.

Results: Compared to the males with normal FBG $\left(3.9 \leqslant \mathrm{FBG}<6.1 \mathrm{mmol}^{-1}\right)$, the males with impaired fasting glucose (IFG: $6.1 \leqslant \mathrm{FBG}<7.0 \mathrm{mmoll}^{-1}$ ) and diabetes mellitus (DM: FBG $\geqslant 7.0 \mathrm{mmol}^{-1}$ ) had a $60 \%(95 \% \mathrm{Cl}: 1.09-2.35)$ and a $58 \%(95 \% \mathrm{Cl}$ : 1.07-2.34) higher risk of incident PLC, respectively. Subgroup analysis found that IFG increased the risk of PLC among the nonsmoker ( $\mathrm{HR}=1.73,95 \% \mathrm{Cl}: 1.01-2.98)$ and current alcohol drinker $(\mathrm{HR}=1.80,95 \% \mathrm{Cl}: 1.03-3.16)$. While DM increased the risk of $\mathrm{PLC}$ especially among the males with normal $\mathrm{BMI}\left(<25 \mathrm{~kg} \mathrm{~m}^{-2}\right)(\mathrm{HR}=1.76,95 \% \mathrm{Cl}: 1.05-2.94)$ and the HBV negativity $(\mathrm{HR}=1.89$, $95 \% \mathrm{Cl}$ : 1.16-3.09), RCS analysis showed a positive non-linearly association between the FBG levels and the risk of PLC ( $p$-overall $=0.041$, $p$-non-linear $=0.049)$.

Conclusions: Increased FBG may be an important and potentially modifiable exposure that could have key scientific and clinical importance for preventing PLC development.

Primary liver cancer (PLC) is the fifth most common incident cancer and second most common cause of cancer death in males around the world. It is a major cancer especially in China where over $50 \%$ of the estimated 554000 new cancer cases and 521000 cancer deaths worldwide occurred in 2012, according to the estimation of GLOBOCAN series of the
International Agency for Research on Cancer (IARC) (Ferlay et al, 2015).

Several studies have demonstrated that abnormal fasting blood glucose (FBG) levels were related to the risks of non-communicable diseases (Sarwar et al, 2010; Liao et al, 2015), including liver cancer which have been reported since 2005 (Han et al, 2017).

*Correspondence: Professor M Dai; E-mail: daimin2002@hotmail.com or Professor N Li; E-mail: nli@cicams.ac.cn

Received 2 May 2017; revised 27 July 2017; accepted 3 August 2017; published online 5 September 2017

(C) 2017 Cancer Research UK. All rights reserved 0007-0920/17 
However, a consensus regarding the association between FBG level and the risk of PLC has not been reached, leaving evidences to be further accumulated.

The recent study reported that FBG level has been steadily increasing in general population of China (Vaidya et al, 2016). The research on the association of PLC risk to FBG level might be helpful for identifying an important and potentially modifiable exposure of PLC, in additional to hepatitis B virus (HBV) and hepatitis $\mathrm{C}$ virus (HCV) infection, and meaningful for preventing PLC development. Therefore, in the present study, we conducted a large cohort established in the Kailuan group and aim to explore the association between levels of FBG and risk of PLC in Chinese males.

\section{MATERIALS AND METHODS}

Study design and population. The data were obtained from a health examination of employees of the Kailuan Company in the city of Tangshan, Hebei Province, north of China. Tangshan is situated about 90 miles southeast of Beijing and represents the overall Chinese population from a socio-economic perspective (Xue et al, 2013; Wang et al, 2015). Over the past few decades, Kailuan Group has developed a comprehensive company managing coal production, machine manufacture, transportation, chemical production, education and health care, etc. Eleven hospitals are affiliated with the Kailuan Company and in charge of the every 2-year health examination of employees.

Participants who met the criteria as follows were enrolled in the present study: (1) males older than 18 years; (2) signing informed consent; (3) completing the questionnaire interview; (4) providing blood samples at baseline. In case of the potential survival bias, subjects who were diagnosed with any prevalent cancer before baseline checkup were excluded from the study.

The study was performed according to the guidelines of the Helsinki declaration and was approved by the Medical Ethics Committee of Kailuan General Hospital. Informed consent was obtained from all individual participants included in the study.

Exposure assessment and laboratory tests. Face-to-face interviews were performed by trained physicians or nurses for all subjects using standardised questionnaires to collect information of potential risk factors at baseline entry. Smoking was defined as tobacco smoking at least one cigarette per week for more than 6 months. Alcohol drinking was defined as drinking at least once per month for more than 6 months. Body weight and height were measured while participants were wearing light clothes without shoes, and the body-mass index (BMI) was calculated according to the equation that $\mathrm{BMI}=$ weight $(\mathrm{kg}) /$ height $\left(\mathrm{m}^{2}\right)$.

The morning fasting venous blood of all subjects were obtained to detect HBsAg and FBG. The enzyme-linked immunosorbent assay for HBsAg (SHANGHAI KEHUA BIO-ENGINEERING, $\mathrm{KHB}$ ) was applied to detect HBsAg quantitatively. All of the tests were conducted in the central laboratory of the Kailuan General Hospital by standard operating procedure. We divided baseline FBG levels into four categories according to WHO standard: Low FBG (LFBG, $\left.<3.9 \mathrm{mmoll}^{-1}\right)$, the normal $\left(3.9-<6.1 \mathrm{mmoll}^{-1}\right)$, impaired fasting glucose (IFG, $6.1-<7.0 \mathrm{mmoll}^{-1}$ ) and diabetes mellitus (DM, $\geqslant 7.0 \mathrm{mmoll}^{-1}$ ) (WHO, 1999).

Outcome ascertainment. We followed participants beginning at the baseline examination and ending at occurrence of cancer, death, or 31 December 2013, whichever event came first. Incident cancer cases in the cohort were collected by tracking subjects when they participated in the every 2-year routine health examination until 31 December, 2013. In addition, medical records from Tangshan medical insurance system and death certificates from Kailuan social security system were checked yearly to get outcome information that may have been missed. Moreover, the outcome information was further confirmed by checking discharge summaries from the 11 affiliated hospitals where participants were treated and diagnosed once a year (Wang et al, 2015).

The diagnosis of incident liver cancer was confirmed by medical records review by clinical experts. Information of pathological diagnosis, imaging diagnosis (including ultrasonography, computerised tomographic scanning and magnetic resonance imaging), blood biochemical examination and alpha fetoprotein test was collected for the incident PLC cases assessment. Cancers were coded according to the International Classification of Diseases, Tenth Revision (ICD-10) and PLC was coded as $\mathrm{C} 22$.

Statistical analysis. Categorical variables were described by percentages and compared using the Chi-square test. Cox proportional hazards regression models adjusted for suspected confounders were used to calculate $\mathrm{HRs}$ and $95 \%$ confidence intervals (CI) for baseline FBG levels and incident PLC, with adjustments for age group (10-year interval), education level (illiterate or primary school, junior high school, senior high school, and college and above), income status ( $<500$ yuan per month, 500-1000 yuan per month, and $>1000$ yuan per month), HBV infection status (HBsAg negative/positive), BMI (continuous variable), frequency of smoking (non-smoker, ex-smoker, $<1$ cigarette per day, and $\geqslant 1$ cigarette per day), and frequency of alcohol drinking (never and past drinker, $<1$ time per day, and $\geqslant 1$ time per day). Subgroup analyses were performed by HBsAg status, BMI, cigarette smoking status and alcohol drinking status. The restricted cubic spline (RCS) analysis was used in the multivariate Cox proportional hazard model to explore the association between continuous FBG and PLC in the study (Desquilbet and Mariotti, 2010). Addictive model was applied to evaluate the synergisms between FBG level and HBsAg infection (de Jager et al, 2011). Synergism index (S) and its 95\% CI were calculated to assess the deviation of the addictive model of no interaction: $S=($ HR11-1) $/[($ HR01 + HR10)-2]. As the value of $S$ equal to unity represented additivity, value greater than unity was interpreted as super additivity and synergism (Rothman, 1976; Lundberg et al, 1996). As a sensitivity analysis, we further excluded 5420 participants who took antidiabetic medications, including oral antidiabetics use and insulin use, and 85 participants who occurred PLC within the first 2 years after entry to the cohort. The data management and all analyses were conducted using SAS statistical software, version 9.4 (SAS Institute). $P<0.05$ was considered statistically significant.

\section{RESULTS}

Baseline characteristics of participants. Total of 109169 males were recruited in this study with the mean age of 51.33 years. The prevalence of IFG $\left(6.1 \leqslant \mathrm{FBG}<7.0 \mathrm{mmoll}^{-1}\right)$ and DM $\left(\mathrm{FBG} \geqslant 7.0 \mathrm{mmoll}^{-1}\right.$ ) was $9.15 \%$ and $8.64 \%$ among the males, respectively. Selected baseline characteristics of participants in the Kailuan male cohort were listed in Table 1 . The rate of current smoking and alcohol drinking were $42.13 \%$ and $45.46 \%$, respectively, as well as the prevalence of HBsAg was $3.21 \%$ among the population. The FBG levels were higher in older males $(\geqslant 50$ years) and among those who with lower education level (Illiterate or primary school) and $\mathrm{BMI} \geqslant 25.0 \mathrm{~kg} \mathrm{~m}^{-2}$, compared with younger males $(<50)$ and those with higher education level $(P<$ $0.001)$ and lower BMI $(P<0.001)$ (Table 1$)$.

The association between FBG level and PLC risk. By 31 December 2013, a total of 267 newly diagnosed primary liver cancer cases with 659232.27 person years accumulated with a median follow-up of 6.89 years in the Kailuan male cohort. The 
Table 1. Baseline characteristics of males in the Kailuan cohort by fasting blood glucose level, 2006-2013

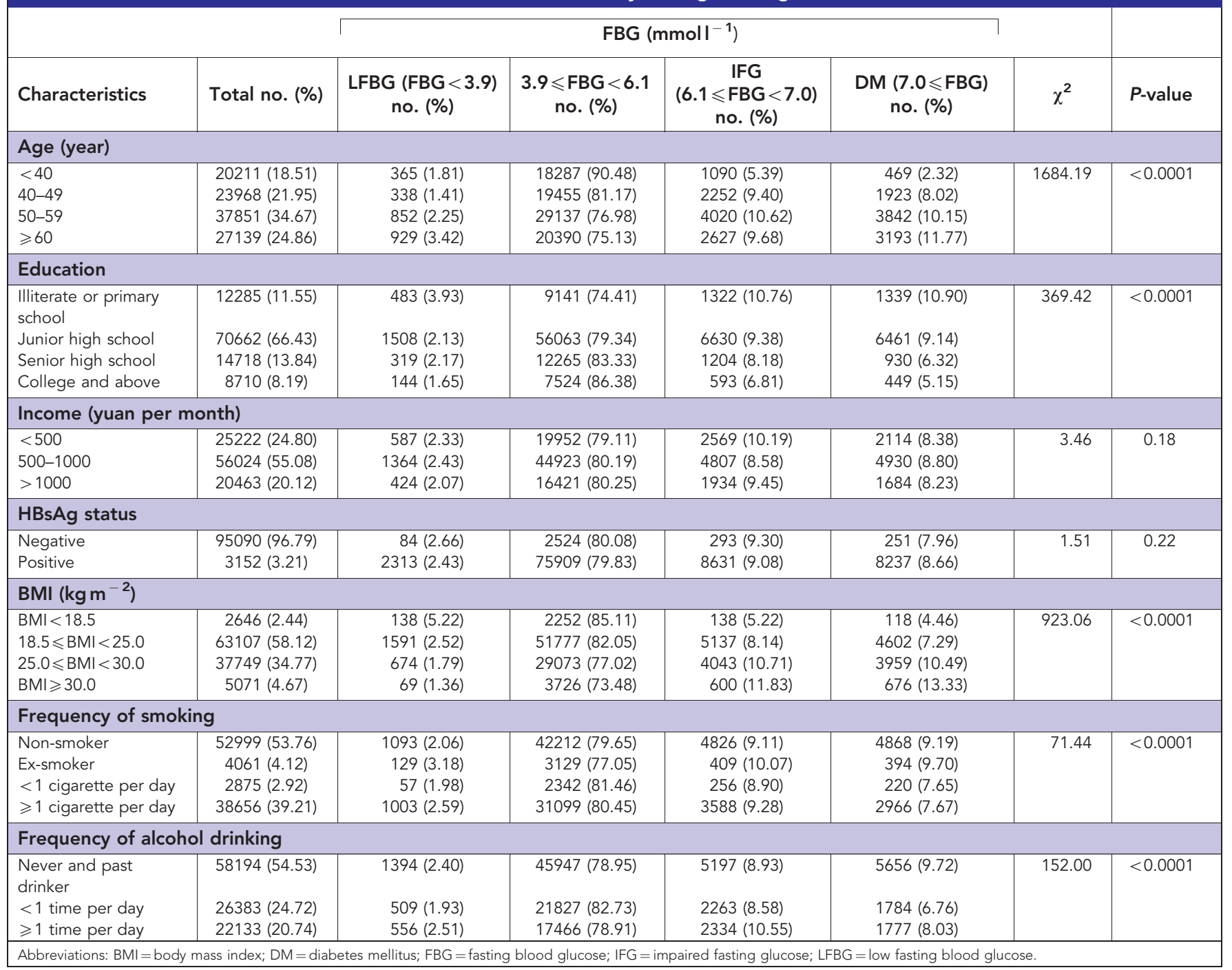

percentage of diagnosis of PLC by pathology and imaging tests were $21.72 \%$ (58/267) and 47.94\% (128/267), respectively. Among the 186 cases with either pathological or imaging diagnosis, there were $164(88.17 \%)$ cases of hepatocellular carcinoma (HCC), 20 (10.75\%) cases of intrahepatic cholangiocarcinoma (ICC) and 2 (1.08\%) uncertified cases.

The males with IFG and the DM were associated with a $56 \%$ (95\% CI: $1.08-2.24)$ and a 51\% (95\% CI: 1.03-2.20) higher risk of incident PLC, compared with the subjects with normal FBG, respectively (Table 2). After adjustment of age, education level, income level, HBsAg infection, BMI, and frequency of smoking and alcohol drinking, significantly higher risk of PLC was found related to IFG $(\mathrm{HR}=1.60,95 \% \mathrm{CI}: 1.09-2.35)$ and $\mathrm{DM}(\mathrm{HR}=1.58$, 95\% CI: 1.07-2.34).

Subgroup analyses showed that the IFG increased the risk of incident PLC especially in the non-smoker ( $\mathrm{HR}=1.73,95 \% \mathrm{CI}$ : $1.01-2.98)$, current drinker ( $\mathrm{HR}=1.80,95 \% \mathrm{CI}: 1.03-3.16)$. While DM could increase the risk of PLC incidence, especially in the males who were $\mathrm{HBsAg}$-negative $(\mathrm{HR}=1.89,95 \% \mathrm{CI}$ : 1.16-3.09) and with normal weight ( $\mathrm{HR}=1.76,95 \% \mathrm{CI}$ : 1.05-2.94) (Table 2).

The RCS model showed a positive dose-response but non-linear association between the level of FBG and the PLC risk among the subject $(P$-overall $=0.041, p$-non-linear $=0.049)($ Figure 1$)$. As the 20th quintile of FBG $\left(4.6 \mathrm{mmoll}^{-1}\right)$ was chosen to be the reference, the HRs of PLC related to FBG levels rise sharply and then steadily when FBG levels was over $7.0 \mathrm{mmoll}^{-1}$.
Interaction analysis between the levels of FBG HBV infection status. The independent and joint effects of FBG levels and HBV infection on the risk of PLC were analysed. The males with $\mathrm{HBsAg}$ positivity had a significantly higher risk of PLC (HR $=31.73,95 \%$ CI: 24.39-41.28) than the males with HBsAg negativity. However, there was no evidence of interaction effect between FBG levels and HBsAg infection status, considering that the estimated synergism index was not statistically significant (IFG: $S=1.59$, $95 \% \mathrm{CI}=0.70-2.15 ; \mathrm{DM}: \mathrm{S}=1.11,95 \% \mathrm{CI}=0.53-2.06)$. Additionally, the interaction effects between FBG levels and smoking (IFG: $\mathrm{S}=1.01,95 \% \mathrm{CI}=0.29-3.52, \mathrm{DM}: \mathrm{S}=1.18,95 \% \mathrm{CI}=$ $0.30-3.84$ ), drinking (IFG: $S=1.89,95 \% \mathrm{CI}=0.06-27.49, \mathrm{DM}$ : $\mathrm{S}=0.85,95 \% \mathrm{CI}=0.05-16.24)$ and $\mathrm{BMI} \geqslant 25.0 \mathrm{~kg} \mathrm{~m}^{-2}$ (IFG: $\mathrm{S}=1.19,95 \% \mathrm{CI}=0.20-5.76, \mathrm{DM}: \mathrm{S}=0.71,95 \% \mathrm{CI}=0.14-5.20)$ were not significant.

Sensitivity analysis. After excluding males with antidiabetic medications use history $(n=5420)$, we found that compared with the males with normal FBG, the males with IFG ( $\mathrm{HR}=1.65,95 \%$ CI: 1.11-2.45) still had an increased risk of all incident PLC cancers. In addition, excluding participants who occurred PLC within the first 2 years after entry to the cohort, there was still a positive association of the risk of PLC related to DM ( $\mathrm{HR}=1.62$, 95\% CI: 1.02-2.59; Table 3). The results of sensitivity analyses concerning the major potential confounders cannot alter the main findings. 
Table 2. The association between fasting blood glucose and primary liver cancer risk in males, Kailuan cohort, 2006-2013

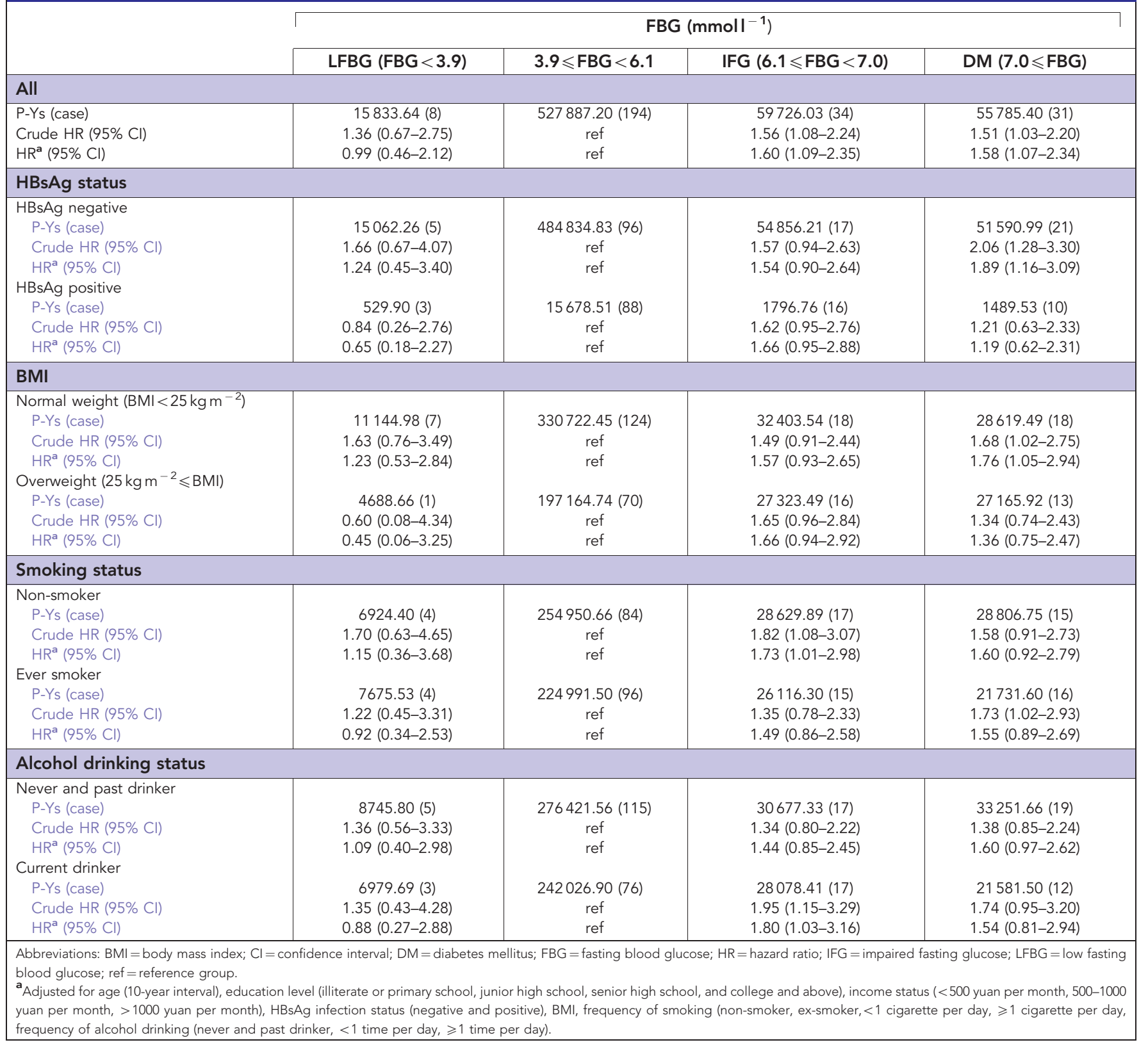

\section{DISCUSSION}

In this large prospective cohort study among Chinese males, we found that FBG levels are modestly associated with increased risk of PLC, which could be modified by HBsAg infection, BMI, tobacco smoking and alcohol drinking status. In addition, FBG level was non-linearly related to PLC risk among target males. To our knowledge, this is the first prospective study to explore the association between the FBG level and the risk of PLC among general males in mainland China.

Findings that high FBG level was associated with a statistically significantly increased risk of primary liver cancer in males of this study are in line with observations in the exiting four prospective cohort studies as follows. The prospective cohort study in Korea found that FBG level of 6.1-6.9 $\mathrm{mmoll}^{-1}$ and $7.0-7.7 \mathrm{mmoll}^{-1}$ for males might increase the risk of liver cancer incidence
$(\mathrm{HR}=1.16,95 \% \mathrm{CI}: 1.07-1.27 ; \mathrm{HR}=1.45,95 \% \mathrm{CI}: 1.24-1.70)$ referred to $\mathrm{FBG}<5.0 \mathrm{mmoll}^{-1}$ (Jee et al, 2005). Compared to the group of $\mathrm{FBG}<5.6 \mathrm{mmoll}^{-1}$ category, a study observed that the risk of HCC in Japanese men and women was 75\% higher in those with $\mathrm{FBG} \geqslant 5.6 \mathrm{mmoll}^{-1}$ (Inoue et al, 2009), while the study based on Korean Multi-Center Cancer Cohort showed that DM increased two-fold risk of liver cancer (Gwack et al, 2007). The study conducted in 140000 adults in Austria demonstrated a strong association between high level of FBG and risk of liver cancer in males $\left(6.1 \leqslant \mathrm{FBG}<6.9 \mathrm{mmoll}^{-1}\right.$ : $\mathrm{HR}=3.50,95 \% \mathrm{CI}: 1.28-9.60$; $\left.\mathrm{FBG} \geqslant 7.0 \mathrm{mmoll}^{-1}: \mathrm{HR}=4.58,95 \% \mathrm{CI}: 1.81-11.62\right)$, in comparison with FBG between 4.2 and $5.2 \mathrm{mmoll}^{-1}$ (Rapp et al, 2006). However, no association was found among 578700 Europeans (Borena et al, 2012), and among the HBV carriers in Taiwan after adjustment of insulin (Chao et al, 2011).

Several possible mechanisms might explain the association between high FBG and increasing risk of PLC. Basic research found 
that high glucose concentration was capable of accelerating tumourigenesis in humans though its damage to DNA (Pereira et al, 2013). Hyperglycaemia and its related conditions, such as chronic oxidative stress and the accumulation of advanced glycation end-products, might act as carcinogenic factors (Abe and Yamagishi, 2008; Qiao et al, 2016). Additionally, glucose catabolism could promote the proliferation of cancer cells by triggering quiescence exit (Laporte et al, 2011), insulin resistance, as well as stimulating insulin-like growth factor I (IGF -1) (Pollak, 2008; Rajpathak et al, 2009) and Erk1/2 phosphorylation (Zhang et al, 2015). Meanwhile, high glucose exposure also enhances the adhesion, migration and invasion of ICC cells via STAT3 activation (Saengboonmee et al, 2016).

The prevalence of HBsAg was 3.21\% in the present study, which was similar to the HBsAg prevalence $(<4 \%)$ among north Chinese reported previously (Yin et al, 2010). As it has been reported widely that $\mathrm{HBsAg}$ has a very close linkage with $\mathrm{HCC}$ or liver cancer incidence (Lin and Kao, 2013; Yang et al, 2016), our study also proved the significant association between HBV positivity and the risk of PLC ( $\mathrm{HR}=31.73$, 95\% CI: 24.39 41.28). The obesity was also reported to be closely associated with glucose concentration ( $\mathrm{Fu}$ et al, 2013; Ek et al, 2015) and liver cancer, which was attributed to insulin resistance and IGF-1 regulating. Furthermore, IARC has classified cigarette smoking as a

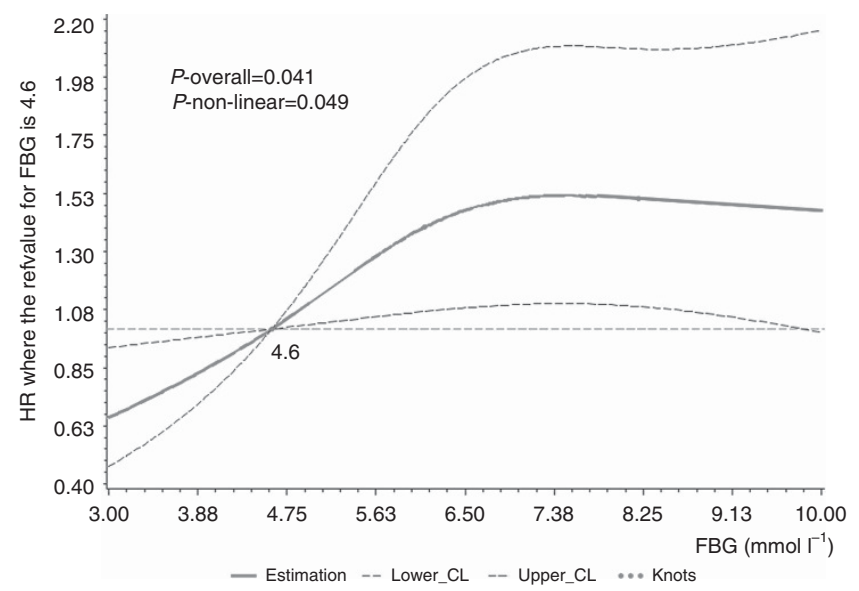

Figure 1. Cubic spline graph of the adjusted HR (represented by solid line) and $95 \% \mathrm{Cl}$ (represented by the dotted lines) for the association between FBG and risk of male primary liver cancer in Kailuan cohort, 2006-2013. Knots: 4.6, 6.1, and 8.2 (95th) of the distribution of fasting blood glucose concentration ( $\mathrm{mmoll}^{-1}$ ); Referent: $4.6 \mathrm{mmoll}^{-1}$, 20th of the distribution of fasting blood glucose concentration. causal risk factor for liver cancer since 2004 (IARC, 2014), considering the DNA damaging effect of several compounds in tobacco smoking and the response of liver plays in the metabolism of these compounds (Staretz et al, 1997; Christmann and Kaina, 2012). Therefore, when these established risk factors play a leading role in the development of PLC, the effect of FBG might be weakened. However, for the HBV negative, non-smokers and the males with normal weight, the increases of FBG showed a significant effect on the development of PLC. The results of the present study showed that increased FBG might be an important and potentially modifiable exposure that could have key scientific and clinical importance for preventing PLC development, in addition to $\mathrm{HBV}$ vaccination, tobacco control and keep healthy weight.

Alcohol drinking may increase $87 \%$ risk of liver cancer incidence (Pei et al, 2008), and attribute to $15.7 \%$ of liver cancer deaths in Chinese population (Fan et al, 2013). Studies have suggested that increased FBG was independent risk factor of the development of fibrosis in alcohol-related hepatic disease because insulin resistance appeared to be a central pathophysiologic feature (Raynard et al, 2002). Besides, it has been reported that alcohol consumption might exacerbate the effect of DM on the development of HCC (Balbi et al, 2010; Raff et al, 2015). Consequently, our finding that increased PLC risk related to evaluated FBG especially among current drinkers was consistent with the studies above.

There are several strengths and limitations that should be noted when interpreting the results of our study. The major limitation of our study was the follow-up time ( $\sim 7.67$ years) was relatively short, which precluded an evaluation of analysis by subtypes of PLC, for example, ICC and HCC, due to small case numbers. Another limitation is the information collection for potential risk factors of PLC was not detailed enough such as the lack of the amount of cigarette smoking and alcohol drinking, which leads to the impossibility to assess the confounders more precisely. HCV was not detected in the study, however, which plays a little less effect on PLC development in Chinese than in other Asian population (de Martel et al, 2015). The most important strength of our study is that it was a large population-based prospective cohort study, which minimises the possibility that the associations observed in our study are due to early disease effects compared with retrospective studies; though as noted, future analyses will be needed to rule out this possibility. In addition, strengths of our study included a high participation $(78.60 \%)$, high percentage of collection of blood samples (99.16\%) and almost $100 \%$ follow-up rate among the study population for well-organised 2 -year health examination of employees, and comprehensive health system including medical records, death certificates and health insurance in City of Tangshan. Moreover, the detection of FBG centralised at

Table 3. Sensitivity analysis of the association between fasting blood glucose and primary liver cancer risk in males, Kailuan cohort, 2006-2013

\begin{tabular}{|c|c|c|c|c|}
\hline & \multicolumn{4}{|c|}{ FBG $\left(\mathrm{mmoll}^{-1}\right)$} \\
\hline & LFBG (FBG < 3.9) & $3.9 \leqslant$ FBG $<6.1$ & IFG $(6.1 \leqslant$ FBG $<7.0)$ & DM $(7.0 \leqslant$ FBG $)$ \\
\hline \multicolumn{5}{|c|}{ Analysis after excluding males with antidiabetic medication use history } \\
\hline Crude HR $(95 \% \mathrm{Cl})$ & $1.37(0.68-2.78)$ & ref & $1.60(1.10-2.33)$ & $1.46(0.90-2.38)$ \\
\hline $\mathrm{HR}^{\mathrm{a}}(95 \% \mathrm{Cl})$ & $0.99(0.46-2.12)$ & ref & $1.65(1.11-2.45)$ & $1.61(0.98-2.66)$ \\
\hline \multicolumn{5}{|c|}{ Analysis after excluding participants who occurred PLC within the first 2 years after entry to the cohort } \\
\hline $\mathrm{HR}^{\mathrm{a}}(95 \% \mathrm{Cl})$ & $0.99(0.40-2.44)$ & ref & $1.47(0.91-2.37)$ & $1.62(1.02-2.59)$ \\
\hline \multicolumn{5}{|c|}{$\begin{array}{l}\text { Abbreviations: } \mathrm{Cl}=\text { confidence interval; } \mathrm{DM}=\text { diabetes mellitus; } \mathrm{FBG}=\text { fasting blood glucose; HR=hazard ratio; IFG =impaired fasting glucose; LFBG }=\text { low fasting blood glucose; } \\
\mathrm{PLC}=\text { primary liver cancer; ref = reference group. } \\
\text { a Adjusted for age (10-year interval), education level (illiterate or primary school, junior high school, senior high school, and college and above), income status ( }<500 \text { yuan per month, } 500-1000 \\
\text { yuan per month, }>1000 \text { yuan per month), HBsAg infection status (negative and positive), BMl, frequency of smoking (non-smoker, ex-smoker, }<1 \text { cigarette per day, } \geqslant 1 \text { cigarette per day, } \\
\text { frequency of alcohol drinking (never and past drinker, }<1 \text { time per day, } \geqslant 1 \text { time per day). }\end{array}$} \\
\hline
\end{tabular}


the central laboratory of Kailuan hospital (Wang et al, 2015), minimising the detection bias.

In summary, our study provides further evidence that higher level of FBG is modestly and non-linearly associated with increased risk of PLC in Chinese males. The findings indicate that the FBG surveillance could be one of the scientific and important ways to identify the high-risk population of PLC. The well control of FBG might be served as a possible primary prevention for further decrease of PLC among the Chinese males who experienced the national vaccination since 1990s and just in the time of steadily increasing of FBG in general Chinese population.

\section{ACKNOWLEDGEMENTS}

This work was supported by National Key R\&D Program of China (grant no 2016YFC1302500), Research Special Fund for Public Welfare Industry of Health (grant no. 201402003), PUMC Youth Fund (grant no. 3332016131), National Natural Science Foundation of China (grant no. 81673265 and 81373079).

\section{CONFLICT OF INTEREST}

The authors declare no conflict of interest.

\section{REFERENCES}

Abe R, Yamagishi S (2008) AGE-RAGE system and carcinogenesis. Curr Pharmaceut Des 14(10): 940-945.

Balbi M, Donadon V, Ghersetti M, Grazioli S, Valentina GD, Gardenal R, Mas MD, Casarin P, Zanette G, Miranda C, Cimarosti P (2010) Alcohol and HCV chronic infection are risk cofactors of type 2 diabetes mellitus for hepatocellular carcinoma in Italy. Int J Environment Res Public Health 7(4): 1366-1378.

Borena W, Strohmaier S, Lukanova A, Bjorge T, Lindkvist B, Hallmans G, Edlinger M, Stocks T, Nagel G, Manjer J, Engeland A, Selmer R, Haggstrom C, Tretli S, Concin H, Jonsson H, Stattin P, Ulmer H (2012) Metabolic risk factors and primary liver cancer in a prospective study of 578,700 adults. Int J Cancer 131(1): 193-200.

Chao LT, Wu CF, Sung FY, Lin CL, Liu CJ, Huang CJ, Tsai KS, Yu MW (2011) Insulin, glucose and hepatocellular carcinoma risk in male hepatitis B carriers: results from 17-year follow-up of a population-based cohort. Carcinogenesis 32(6): 876-881.

Christmann M, Kaina B (2012) O(6)-methylguanine-DNA methyltransferase (MGMT): impact on cancer risk in response to tobacco smoke. Mutat Res 736(1-2): 64-74.

de Jager DJ, de Mutsert R, Jager KJ, Zoccali C, Dekker FW (2011) Reporting of interaction. Nephron Clin Pract 119(2): c158-c161.

de Martel C, Maucort-Boulch D, Plummer M, Franceschi S (2015) Worldwide relative contribution of hepatitis $\mathrm{B}$ and $\mathrm{C}$ viruses in hepatocellular carcinoma. Hepatology (Baltimore, Md) 62(4): 1190-1200.

Desquilbet L, Mariotti F (2010) Dose-response analyses using restricted cubic spline functions in public health research. Stat Med 29(9): 1037-1057.

Ek AE, Rossner SM, Hagman E, Marcus C (2015) High prevalence of prediabetes in a Swedish cohort of severely obese children. Pediatr Diabetes 16(2): 117-128.

Fan JH, Wang JB, Jiang Y, Xiang W, Liang H, Wei WQ, Qiao YL, Boffetta P (2013) Attributable causes of liver cancer mortality and incidence in china. Asian Pac J Cancer prev 14(12): 7251-7256.

Ferlay J, Soerjomataram I, Dikshit R, Eser S, Mathers C, Rebelo M, Parkin DM, Forman D, Bray F (2015) Cancer incidence and mortality worldwide: sources, methods and major patterns in GLOBOCAN 2012. Int J Cancer 136(5): E359-E386.

Fu S, Luo L, Ye P, Liu Y, Zhu B, Zheng J, Bai Y, Bai J (2013) Overall and abdominal obesity indicators had different association with central arterial stiffness and hemodynamics independent of age, sex, blood pressure, glucose, and lipids in Chinese community-dwelling adults. Clin Interv Aging 8: 1579-1584.

Gwack J, Hwang SS, Ko KP, Jun JK, Park SK, Chang SH, Shin HR, Yoo KY (2007) Fasting serum glucose and subsequent liver cancer risk in a Korean prospective cohort. J Prev Med Public Health 40(1): 23-28.

Han H, Zhang T, Jin Z, Guo H, Wei X, Liu Y, Chen Q, He J (2017) Blood glucose concentration and risk of liver cancer: systematic review and metaanalysis of prospective studies. Oncotarget 8(30): 50164-50173.

IARC (2014) IARC monographs on the evaluation of carcinogenic risks to humans, tobacco smoke and involuntary smoking. Vol. 83. IARC: Lyon, France, pp1187. Available at: https://monographs.iarc.fr/ENG/ Monographs/vol83/mono83.pdf.

Inoue $\mathrm{M}$, Kurahashi N, Iwasaki M, Tanaka Y, Mizokami M, Noda M, Tsugane S (2009) Metabolic factors and subsequent risk of hepatocellular carcinoma by hepatitis virus infection status: a large-scale populationbased cohort study of Japanese men and women (JPHC Study Cohort II). Cancer Causes Control 20(5): 741-750.

Jee SH, Ohrr H, Sull JW, Yun JE, Ji M, Samet JM (2005) Fasting serum glucose level and cancer risk in Korean men and women. Jama 293(2): 194-202.

Laporte D, Lebaudy A, Sahin A, Pinson B, Ceschin J, Daignan-Fornier B, Sagot I (2011) Metabolic status rather than cell cycle signals control quiescence entry And Exit. J Cell Biol 192(6): 949-957.

Liao WC, Tu YK, Wu MS, Lin JT, Wang HP, Chien KL (2015) Blood glucose concentration and risk of pancreatic cancer: systematic review and doseresponse meta-analysis. BMJ (Clinical research ed) 349: g7371.

Lin CL, Kao JH (2013) Risk stratification for hepatitis B virus related hepatocellular Carcinoma. J Gastroenterol Hepatol 28(1): 10-17.

Lundberg M, Fredlund P, Hallqvist J, Diderichsen F (1996) A SAS program calculating three measures of interaction with confidence intervals. Epidemiology (Cambridge, Mass) 7(6): 655-656.

Pei GJ, Li FU, Cui YL (2008) Meta-analysis on the association of hepatocellular carcinoma with alcohol drinking among Chinese people. Modern Preventive Medicine 35(14): 2626-2627.

Pereira CS, Molz P, Palazzo RP, de Freitas TA, Maluf SW, Horta JA, Pra D, Franke SI (2013) DNA damage and cytotoxicity in adult subjects with prediabetes. Mutat Res 753(2): 76-81.

Pollak M (2008) Insulin and insulin-like growth factor signalling in neoplasia. Nat Rev Cancer 8(12): 915-928.

Qiao Y, Zhang X, Zhang Y, Wang Y, Xu Y, Liu X, Sun F, Wang J (2016) High glucose stimulates tumourigenesis in hepatocellular carcinoma cells through AGER-dependent O-GlcNAcylation of c-Jun. Diabetes 65(3): 619-632.

Raff EJ, Kakati D, Bloomer JR, Shoreibah M, Rasheed K, Singal AK (2015) Diabetes mellitus predicts occurrence of cirrhosis and hepatocellular cancer in alcoholic liver and non-alcoholic fatty liver diseases. J Clin Transl Hepatol 3(1): 9-16.

Rajpathak SN, Gunter MJ, Wylie-Rosett J, Ho GY, Kaplan RC, Muzumdar R, Rohan TE, Strickler HD (2009) The role of insulin-like growth factor-I and its binding proteins in glucose homeostasis and type 2 diabetes. Diabetes/metab res rev 25(1): 3-12.

Rapp K, Schroeder J, Klenk J, Ulmer H, Concin H, Diem G, Oberaigner W, Weiland SK (2006) Fasting blood glucose and cancer risk in a cohort of more than 140,000 adults in Austria. Diabetologia 49(5): 945-952.

Raynard B, Balian A, Fallik D, Capron F, Bedossa P, Chaput JC, Naveau S (2002) Risk factors of fibrosis in alcohol-induced liver disease. Hepatology (Baltimore, $M d$ ) 35(3): 635-638.

Rothman KJ (1976) The estimation of synergy or antagonism. Am J Epidemiol 103(5): 506-511.

Saengboonmee C, Seubwai W, Pairojkul C, Wongkham S (2016) High glucose enhances progression of cholangiocarcinoma cells via STAT3 activation. Sci Rep 6: 18995.

Sarwar N, Gao P, Seshasai SR, Gobin R, Kaptoge S, Di Angelantonio E, Ingelsson E, Lawlor DA, Selvin E, Stampfer M, Stehouwer CD, Lewington S, Pennells L, Thompson A, Sattar N, White IR, Ray KK, Danesh J (2010) Diabetes mellitus, fasting blood glucose concentration, and risk of vascular disease: a collaborative meta-analysis of 102 prospective studies. Lancet (London, England) 375(9733): 2215-2222.

Staretz ME, Murphy SE, Patten CJ, Nunes MG, Koehl W, Amin S, Koenig LA, Guengerich FP, Hecht SS (1997) Comparative metabolism of the tobaccorelated carcinogens benzo[a]pyrene, 4-(methylnitrosamino)-1-(3-pyridyl)1-butanone, 4-(methylnitrosamino)-1-(3-pyridyl)-1-butanol, and N'nitrosonornicotine in human hepatic microsomes. Drug Metab Dispos 25(2): 154-162. 
Vaidya A, Cui L, Sun L, Lu B, Chen S, Liu X, Zhou Y, Liu X, Xie X, Hu FB, Wu S, Gao X (2016) A prospective study of impaired fasting glucose and type 2 diabetes in China: the Kailuan study. Medicine 95(46): e5350.

Wang G, Li N, Chang S, Bassig BA, Guo L, Ren J, Su K, Li F, Chen S, Wu S, Zou Y, Dai M, Zheng T, He J (2015) A prospective follow-up study of the relationship between C-reactive protein and human cancer risk in the Chinese Kailuan Female Cohort. Cancer Epidemiol Biomarkers Prev 24(2): 459-465.

WHO (1999) Definition, Diagnosis and Classification Of Diabetes Mellitus and its Complications: report of a WHO consultation. Part 1: Diagnosis and Classification of Diabetes Mellitus. World Health Organization, Department of Noncommunicable Disease Surveillance: Geneva, Switzerland.

Xue H, Wang J, Hou J, Zhu H, Gao J, Chen S, Wang Y, Chen Y, Wu S (2013) Association of ideal cardiovascular metrics and serum high-sensitivity C-reactive protein in hypertensive population. PLoS One 8(12): e81597.

Yang Y, Gao J, Li HL, Zheng W, Yang G, Zhang W, Ma X, Tan YT, Rothman N, Gao YT, Chow WH, Shu XO, Xiang YB (2016) Dose-response association between hepatitis B surface antigen levels and liver cancer risk in Chinese men and women. Int J Cancer 139(2): 355-362.
Yin J, Zhang H, He Y, Xie J, Liu S, Chang W, Tan X, Gu C, Lu W, Wang H, Bi S, Cui F, Liang X, Schaefer S, Cao G (2010) Distribution and hepatocellular carcinoma-related viral properties of hepatitis B virus genotypes in Mainland China: a community-based study. Cancer Epidemiol Biomarkers Prev 19(3): 777-786.

Zhang Q, Jiang K, Li Y, Gao D, Sun L, Zhang S, Liu T, Guo K, Liu Y (2015) Histidine-rich glycoprotein function in hepatocellular carcinoma depends on its $\mathrm{N}$-glycosylation status, and it regulates cell proliferation by inhibiting Erk1/2 phosphorylation. Oncotarget 6(30): 30222-30231.

This work is published under the standard license to publish agreement. After 12 months the work will become freely available and the license terms will switch to a Creative Commons AttributionNonCommercial-Share Alike 4.0 Unported License. 